\title{
Mother's Knowledge and Behaviour Towards Oral Health During Pregnancy
}

\author{
Anandina Irmagita Soegyanto ${ }^{1}$, Ratu Nabila Larasati ${ }^{1}{ }^{(}$, Yuniardini Septorini Wimardhani ${ }^{2}$, \\ Buğra Özen ${ }^{3}$
}

\begin{abstract}
'Department of Oral Medicine, Faculty of Dentistry, Universitas Indonesia, Jakarta, Indonesia.
${ }^{2}$ Cluster of Clinical Epidemiology and Clinical Studies in Dentistry, Faculty of Dentistry, Universitas Indonesia, Depok, Indonesia.

${ }^{3}$ Department of Pediatric Dentistry, Faculty of Dentistry, Altinbas University, Istanbul, Turkey.
\end{abstract}

Author to whom correspondence should be addressed: Anandina Irmagita Soegyanto, Department of Oral Medicine, Faculty of Dentistry, Universitas Indonesia, Jakarta, Indonesia. Phone: +622131930270 - Extension 108. E-mail: anandina.irmagita74@ui.ac.id.

Academic Editor: Alessandro Leite Cavalcanti

Received: 05 March 2020 / Accepted: 27 May 2020 / Published: 19 June 2020

How to cite this article: Soegyanto AI, Larasati RN, Wimardhani YS, Özen B. Mother's knowledge and behaviour
towards oral health during pregnancy. Pesqui Bras Odontopediatria Clín Integr. 2020; $20: e 5647$.
https://doi.org/10.1590/pboci.2020.113

\begin{abstract}
Objective: To evaluate the knowledge and behaviour of mothers in maintaining their oral health during pregnancy. Material and Methods: This study included 167 women in five community primary health centres in Central Jakarta whose last child ranged between 0-59 months. The participants were asked to fill the questionnaire "Knowledge and Behaviour Towards Oral Health during Pregnancy" (KBOHP). This questionnaire assessed the knowledge and behaviour in maintaining oral health during pregnancy. Results: Almost $80 \%$ of participants reported that they had government dental health coverage. Only about $16 \%$ of participants reported that they visit dentist before pregnancy and only about $32 \%$ of the participants reported to have oral health problems during pregnancy. Although they have oral health problems, only $18 \%$ of them visited the dentists during pregnancy. Only $33 \%$ of the participants knew that the periodontal problems can affect pregnancy outcome, and $54.5 \%$ of participants had never heard of a possible connection between oral health and pregnancy. About $74 \%$ of participants reported that they never had specific oral health care instruction during pregnancy. Participants who received oral health instruction from their health providers also tend to have dental visit during pregnancy. Conclusion: Knowledge and behaviour towards oral health during pregnancy in this population was still low. A program that is developed to improve knowledge and behaviour in maintaining oral health during pregnancy is needed.
\end{abstract}

Keywords: Attitude to Health; Health Knowledge, Attitudes, Practice; Oral Hygiene. 


\section{Introduction}

In the pregnancy period, there are many complex physiological changes that affect oral health [1]. Oral disease during pregnancy is an important issue since it is related to many conditions such as adverse pregnancy/birth outcomes, early childhood caries, as well as chronic diseases [2]. Higher prevalence and severity of gingival inflammation in pregnancy have been reported. The changes in the level of sex hormones plasma regulation have led to a significant effect on the periodontal tissues as well as their response to the bacteria and dental plaque [3]. Periodontal disease in pregnancy has been indicated as a risk factor for poor pregnancy outcomes such as pre-term birth and low birth weight [4-7].

Despite the fact that oral diseases during pregnancy influence pregnancy outcomes, it was found that there is a tendency for not receiving dental treatment during the period [8]. Several factors related to the issue that limits access of dental care during pregnancy have been postulated. Some of them are lacking of insurance coverage, unfounded beliefs that dental treatment during pregnancy is not safe, and the unreadiness of health providers to give treatment [9,10]. Currently, many studies have shown that increasing adverse pregnancy outcome does not influence by routine preventive, diagnostic, restorative dental treatment, including periodontal therapy [8].

Accordingly, the awareness and behaviour related to oral health care during pregnancy and after pregnancy, are important issues for women to take care of themselves and their children [11]. Many educational programs on pregnant women that are provided by dentists, physicians and midwives would prevent oral diseases in both mothers and influencing the children's future of oral health [11,12]. The program normally designed to suit the need of the community. In order to design the educational program that matches with the community, the women's knowledge related to the association between oral health and pregnancy outcome has to be assessed. Several studies have been done in different countries; however, studies from Indonesia are lacking [13-15]. Therefore, the study aimed to evaluate the Indonesian women's knowledge and behaviour towards oral health during pregnancy.

\section{Material and Methods}

Study Design and Sample

This study was a cross-sectional questionnaire-based study evaluating the knowledge and behaviour towards oral health during pregnancy. This study invited women who were attending their children's routine checkups at 5 community primary health centres in Central Jakarta. All women who had a child or children aged 0-59 months were asked to participate in the study.

\section{Data Collection}

They were asked to fill out the Knowledge and Behaviour towards Oral Health during Pregnancy (KBOHP) questionnaire that was used developed and used in a previous study [14]. Any participants who did not fill the questionnaire completely were excluded from the study.

\section{Data Analysis}

Data were analyzed using IBM SPSS Statistics for Windows Software, version 20 (IBM Corp., Armonk, NY, USA). Descriptive statistics were used to calculate the absolute and relative frequencies, mean and standard deviation. Chi-square was used to test associations between categorical variables, with significance level set at $5 \%$. 


\section{Ethical Aspects}

This study was approved by the Ethical Committee of Faculty of Dentistry, Universitas Indonesia (Protocol No. 011031018 ). Participation was voluntary and they were informed about the study and signed the consent form.

\section{Results}

One hundred and sixty-seven women who met the inclusion criteria agreed to participate in the study. The characteristic of the participants was shown in Table 1. The mean age of the participants was $33 \pm 5.22$ years old. Among women aged $\leq 24$ Years, the mean age was 22.33 ( \pm 0.94$)$, among participants aged 25-29 Years the mean was 27.29 ( \pm 1.39$)$ and in those aged $\geq 30$ Years, 35.52 ( \pm 4.04$)$. Sixty percent had high school as the highest degree of education. The mean age of their last child was $26.6 \pm 16.38$ months. Almost $80 \%$ of participants reported that they had government dental health coverage. Almost all participants of this study reported that they brush their teeth more than once a day. However, only $5.4 \%$ of participants reported daily dental flossing and $36.5 \%$ who use oral rinse product at least once a week.

Table 1. Demographic characteristics and oral hygiene habits.

\begin{tabular}{lcc}
\hline \multicolumn{1}{c}{ Variables } & N & $\%$ \\
\hline Age Group & 3 & 1.8 \\
$\leq 24$ Years & 42 & 25.1 \\
25-29 Years & 122 & 73.1 \\
$\geq 30$ Years & & \\
Dental Insurance & 129 & 77.2 \\
$\quad$ Yes & 38 & 22.8 \\
No & & \\
Level of Education & 18 & 10.8 \\
Primary School & 33 & 19.8 \\
Primary School & 97 & 58.1 \\
Secondary School & 12 & 7.2 \\
High School & 7 & 4.2 \\
Diploma & & \\
Toothbrushing & 3 & 1.8 \\
Once a Day & 164 & 98.2 \\
More Than Once a Day & & \\
Daily Use of the Inter-Proximal Cleaning Aids (Dental Floss) & 9 & 5.4 \\
Yes & 158 & 94.6 \\
$\quad$ No & & \\
Use of Oral Rinse Products at Least Once a Week & 61 & 36.5 \\
Yes & 106 & 63.5 \\
No & & \\
\hline
\end{tabular}

The status of oral health and dental care problems during pregnancy is described in Table 2. Only about $16 \%$ of participants reported that they visit the dentist before pregnancy and only about $32 \%$ of the participants reported having oral health problems during pregnancy. Despite the fact that they have oral health problems, only $18 \%$ of them visited the dentists during pregnancy. There are many reasons that limit their visit to the dentist and the most common reason was they thought that the gingiva condition would recover soon after the pregnancy.

The participants' knowledge and beliefs related to oral health during pregnancy were shown in Table 3. Only about $8 \%$ of participants still believe the phrase "A tooth for a baby"; however, there was about $40 \%$ of participants believe that calcium will be drawn out of mother's teeth by the developing fetus. Furthermore, 
only $33 \%$ of the participants knew that periodontal problems can affect pregnancy outcome, and $54.5 \%$ of participants had never heard of a possible connection between oral health and pregnancy. Of the participants who ever heard of a possible connection between oral health and pregnancy, only $24 \%$ reported that they heard it from their medical doctors or dentists. Midwives and gynecologists were reported as the two most common health care providers who were visited by the participants. However, about $74 \%$ of participants reported that they never had specific oral health care instruction during pregnancy. Of the 44 (26.3\%) participants who received oral health pregnancy, the majority (37.7\%) got it from their midwife.

Table 2. Oral health problems and dental care of participants during pregnancy.

\begin{tabular}{|c|c|c|}
\hline Questions & $\begin{array}{c}\text { Yes } \\
\mathrm{N}(\%)\end{array}$ & $\begin{array}{c}\text { No } \\
\text { N (\%) }\end{array}$ \\
\hline Did you experience any oral health problems during your pregnancy? & $53(31.7)$ & $114(68.3)$ \\
\hline Did you visit your dentist regularly before your pregnancy? & $26(15.6)$ & $141(84.4)$ \\
\hline Did you visit your dentist during your pregnancy? & $31(18.6)$ & $136(81.4)$ \\
\hline If the answer is 'no', give one closest reason on why didn't you go to the dentist & \multirow{2}{*}{\multicolumn{2}{|c|}{$16(9.6)$}} \\
\hline Because I thought that my gingiva would recover soon & & \\
\hline $\begin{array}{l}\text { Because I know from my previous pregnancy experience that oral health problems could } \\
\text { be related to pregnancy }\end{array}$ & \multicolumn{2}{|c|}{$6(3.6)$} \\
\hline $\begin{array}{l}\text { Because a dentist might use local anesthetics or prescribe antibiotics without consulting } \\
\text { my medical doctor }\end{array}$ & \multicolumn{2}{|c|}{$4(2.4)$} \\
\hline Because a dentist could not provide any treatment during my pregnancy & \multicolumn{2}{|c|}{$3(1.8)$} \\
\hline No reason & \multicolumn{2}{|c|}{$11(6.6)$} \\
\hline Because I didn’t experience any oral health problems during my pregnancy & \multicolumn{2}{|c|}{$86(51.5)$} \\
\hline Other reason & \multicolumn{2}{|c|}{$10(6.0)$} \\
\hline
\end{tabular}

Table 3. Participants' knowledge regarding associations between pregnancy outcome and oral health.

\begin{tabular}{|c|c|c|}
\hline Questions & $\begin{array}{c}\text { Yes } \\
\mathrm{N}(\%)\end{array}$ & $\begin{array}{c}\text { No } \\
\text { N (\%) }\end{array}$ \\
\hline Do you believe in the truth of the saying 'A tooth for a baby'? & $12(7.2)$ & $155(92.8)$ \\
\hline Do you believe calcium will be drawn out of your teeth by the developing fetus? & $68(40.7)$ & $99(59.3)$ \\
\hline Do you believe periodontal problems can affect pregnancy outcome? & $55(32.9)$ & $112(67.1)$ \\
\hline Have you heard about a possible connection between oral health and pregnancy? & $76(45.5)$ & $91(54.5)$ \\
\hline \multicolumn{3}{|l|}{ If the answer is 'yes', where did you hear this?* } \\
\hline I read it in a book, magazine or the internet & \multicolumn{2}{|c|}{$28(29.2)$} \\
\hline My medical doctor told me about it & \multicolumn{2}{|c|}{$15(15.6)$} \\
\hline My dentist told me about it & \multicolumn{2}{|c|}{$9(9.4)$} \\
\hline I heard it from people around me & \multicolumn{2}{|c|}{$31(32.3)$} \\
\hline From my previous experience with pregnancy & \multicolumn{2}{|c|}{$10(10.4)$} \\
\hline Other & \multicolumn{2}{|c|}{$3(3.1)$} \\
\hline \multicolumn{3}{|l|}{ During pregnancy, which health care providers did you visit?* } \\
\hline General practitioners & \multicolumn{2}{|c|}{$43(15.5)$} \\
\hline Obstetricians & \multicolumn{2}{|c|}{$95(34.2)$} \\
\hline Midwife & \multicolumn{2}{|c|}{$112(40.3)$} \\
\hline Dentist & \multicolumn{2}{|c|}{$28(10.1)$} \\
\hline $\begin{array}{l}\text { Did you receive any instruction on oral health care from your health care provider during } \\
\text { your pregnancy? }\end{array}$ & $44(26.3)$ & $123(73.7)$ \\
\hline \multicolumn{3}{|l|}{ During pregnancy, what health care provider gives you instructions for oral health care?** } \\
\hline General practitioners & \multicolumn{2}{|c|}{$3(5.7)$} \\
\hline Obstetricians & \multicolumn{2}{|c|}{$16(30.2)$} \\
\hline Midwife & \multicolumn{2}{|c|}{$20(37.7)$} \\
\hline Dentist & \multicolumn{2}{|c|}{$14(26.4)$} \\
\hline
\end{tabular}

*Answer could be more than one. 
We further distribute the participants' dental visit during pregnancy according to their oral health care behaviour, knowledge and beliefs, insurance/oral health problems/oral health instruction (Table 4). It showed that women who never or rarely use oral rinse products and do not have a regular dental visit before pregnancy tend to not going to the dentist during their pregnancy and the difference was statistically significant. There was no statistically significant difference between beliefs and dental visit during pregnancy. Participants' beliefs that periodontal problems can affect the pregnancy outcome were not the reason for them havind dental visits during pregnancy. Likewise, participants who have heard of a possible connection between oral health and pregnancy still do not visit the dentist during pregnancy. A high number of participants with insurance ownership did also not make them have dental visit during pregnancy. Having oral health problems during pregnancy and receiving oral health instruction from their health provider also tend to have dental visit during pregnancy and the difference was statistically significant.

Table 4. Oral health care behaviour, knowledge and beliefs, insurance/oral health problems/oral health instruction and its relation to dental visit during pregnancy.

\begin{tabular}{|c|c|c|c|c|}
\hline \multirow[b]{2}{*}{ Variables } & \multicolumn{3}{|c|}{ Dental Visit During Pregnancy } & \multirow[b]{2}{*}{ p-value } \\
\hline & Categories & $\begin{array}{c}\text { Yes } \\
\mathrm{N}(\%)\end{array}$ & $\begin{array}{c}\text { No } \\
\mathrm{N}(\%)\end{array}$ & \\
\hline \multicolumn{5}{|l|}{ Oral Hygiene Practice/Behaviour } \\
\hline \multirow[t]{2}{*}{ Brushing teeth } & $>1$ & $31(18.9)$ & $133(81.1)$ & 1.00 \\
\hline & $<1$ & $\mathrm{o}(\mathrm{O})$ & $3(100)$ & \\
\hline \multirow[t]{2}{*}{ Daily use of the interproximal cleaning aids (dental floss) } & Yes & $3(33.3)$ & $6(66.7)$ & 0.37 \\
\hline & No & $28(17.7)$ & $130(82.3)$ & \\
\hline \multirow[t]{2}{*}{ Use of oral rinse products at least once a week } & Yes & $18(29.5)$ & $43(70.5)$ & $0.01^{*}$ \\
\hline & No & $13(12.3)$ & $93(87.7)$ & \\
\hline \multirow[t]{2}{*}{ Visit dentist regulary before pregnancy } & Yes & $10(38.5)$ & $16(61.5)$ & 0.11 \\
\hline & No & $21(14.9)$ & $120(85.1)$ & \\
\hline \multicolumn{5}{|l|}{ Knowledge and Beliefs } \\
\hline \multirow[t]{2}{*}{ Believe in the truth of the saying 'A tooth for a baby' } & Yes & $3(25)$ & $9(75)$ & 0.47 \\
\hline & No & $28(18.1)$ & $127(81.9)$ & \\
\hline \multirow[t]{2}{*}{ Believe calcium will be drawn out of teeth by the developing fetus } & Yes & $14(20.6)$ & $54(79.4)$ & 0.72 \\
\hline & No & $17(17.2)$ & $82(82.8)$ & \\
\hline \multirow[t]{2}{*}{ Believe periodontal problems can affect pregnancy outcome } & Yes & $12(21.8)$ & $43(78.2)$ & 0.58 \\
\hline & No & $19(17)$ & $93(83)$ & \\
\hline \multirow{2}{*}{$\begin{array}{l}\text { Have heard about the possible connection between oral health and } \\
\text { pregnancy }\end{array}$} & Yes & $16(21.1)$ & $60(78.9)$ & 0.58 \\
\hline & No & $15(16.5)$ & $76(83.5)$ & \\
\hline \multicolumn{5}{|l|}{ Insurance/Oral Health Problems/Oral Health Instruction } \\
\hline \multirow[t]{2}{*}{ Dental insurance } & Yes & $22(17.1)$ & $107(82.9)$ & 0.49 \\
\hline & No & $9(23.7)$ & $29(76.3)$ & \\
\hline \multirow[t]{2}{*}{ Experiencing oral health problems during pregnancy } & Yes & $22(41.5)$ & $31(58.5)$ & $<0.01^{*}$ \\
\hline & No & $9(7.9)$ & $105(92.1)$ & \\
\hline \multirow{2}{*}{$\begin{array}{l}\text { Receive instruction on oral health care from health care provider } \\
\text { during pregnancy }\end{array}$} & Yes & $21(47.7)$ & $23(52.3)$ & $<0.01 *$ \\
\hline & No & $10(8.1)$ & $113(91.9)$ & \\
\hline
\end{tabular}

* Statistically Significant.

\section{Discussion}

This study had evaluated knowledge and behaviour towards oral health during pregnancy in a sample of Indonesian women using a questionnaire that was used in a previous study [14]. This study also showed that dental care as one aspect of antenatal care had been neglected. There was a low level of dental care usage by women when they were pregnant. Although most participants have dental health insurance, only one-fourth of them visit the dentist during pregnancy. The result is consistent with the study conducted in England that 
shows a free dental care program during pregnancy did not has a major influence in encouraging the mother to visit a dentist [16]. On the other hand, a study in Canada showed that women with insurance were 6.6 more likely to visit dentist during pregnancy [17].

Almost all women in the study reported that they had good oral health. However, this is one limitation of this study. In attempts to reduce the possibility of an untrue answer, at the beginning of the study, we had informed the participants to answer the question according to the exact condition. The status of the participants' oral health would have been confirmed by clinical examination. Of the participants who reported to have oral health problems, not all of them reported to visit a dentist to receive proper dental care. The results of this study were similar to other studies showing that women tend to receive less dental care in the pregnancy period $[13,18,19]$.

Many factors could limit the usage of dental care during pregnancy. This study showed that knowledge and beliefs of both women, care providers including physicians, midwives, and dentists may limit the access to dental care during pregnancy [1,12,20]. Some studies revealed that some dentists still felt uncertain about safety when providing dental procedures, which made them hesitant to treat the patient [10]. This should be the basis of designing a continuing education program to socialize the consensus statement on oral health care during pregnancy, covering aspects of importance and safety of routine dental care that has been issued in 2012 [2,8,21]. Some educational strategies also needed that aiming for the oral health competencies among related health care workers who provide antenatal care [1,12].

In this study, we found that the level of knowledge of oral health during pregnancy was low. The participants did not feel that the examination to the dentist was something to be done during pregnancy. They had never had oral health education prior to pregnancy and did not know the relationship between oral health and pregnancy outcome. This is similar with the finding of previous study as they also thought their oral condition would recover soon and it was part of normal changes in their oral cavity [18]. Some of the participants were afraid that the dental procedure would not be safe for pregnant women as well as lack of knowledge about the adverse effects of untreated oral health problems on pregnancy outcome. This result was similar to another study in Australia, which studied a sample of pregnant women from Afghan and Sri Lanka and a study in Turkish women [14,22]

The participants of this study visited many health care providers during their pregnancy. Midwives and gynecologists/obstetricians were the most commonly visited health care providers by the participants. However, only about one-third of them had information about relationship between oral health and pregnancy outcome as well as the information about oral health instruction during pregnancy. This may be caused that not all health care providers in antenatal care have oral health care competencies [12]. As the dentist was not routinely visited by the women during their pregnancy, an increase of usage may be possible by having gynaecologists-midwives and dentists collaboration. Referral from gynaecologists or midwives to dentists as one of antenatal care for women in their pregnancy. In Jakarta, the utilization of government antenatal facilities reached $97.01 \%$ in 2016 [23]. The high utilization of these facilities can be used as an educational oral health care forum for pregnant women. Integrated oral health care programs with other health care provider in the centres should be done.

\section{Conclusion}

Indonesian mother's knowledge and behavior towards oral health during pregnancy are still low and dental care usage during the period was also limited. Several factors that limit access have been postulated and 
there is a need for all health care providers involved in antenatal care to have a better role in educating women on oral health care during pregnancy.

\section{Authors' Contributions}

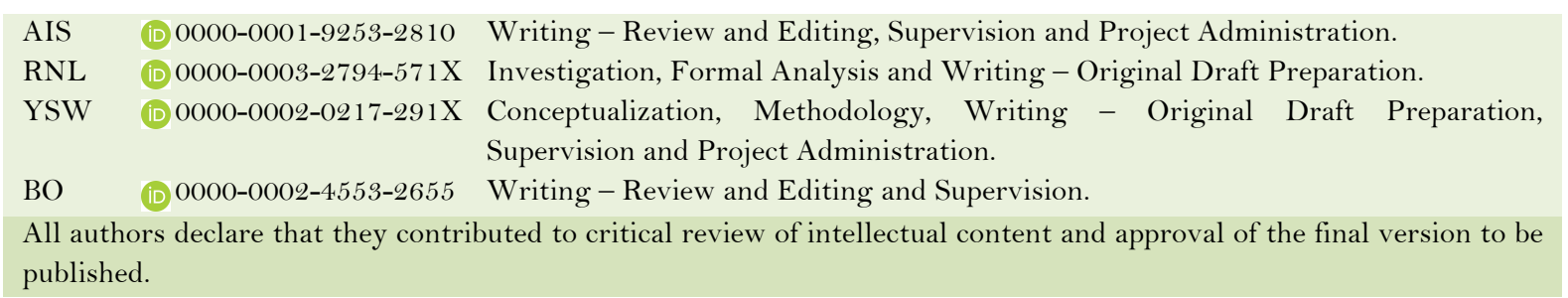

\section{Financial Support}

Universitas Indonesia Research (Hibah PITTA A, 2019) Grant no. NKB-0421/UN2.R3.1/HKP.05.00/2019.

\section{Conflict of Interest}

The authors declare no conflicts of interest.

\section{References}

[1] Hartnett E, Haber J, Krainovich-Miller B, Bella A, Vasilyeva A, Lange Kessler J. Oral health in pregnancy. J Obstet Gynecol Neonatal Nurs 2016; 45(4):565-73. https://doi.org/10.1016/j.jogn.2016.04.005.

[2] Dragan IF, Veglia V, Geisinger ML, Alexander DC. Dental care as a safe and essential part of a healthy pregnancy. Compend Contin Educ Dent 2018; 39(2):86-91.

[3] Wu M, Chen SW, Jiang SY. Relationship between gingival inflammation and pregnancy. Mediators Inflamm 2015; 2015:623427. https://doi.org/10.1155/2015/623427

[4] Han YW. Oral health and adverse pregnancy outcomes - what's next? J Dent Res 2011; 90(3):289-93. https://doi.org/10.1177/0022034510381905

[5] Basha S, Swamy HS, Mohamed RN. Maternal periodontitis as a possible risk factor for preterm birth and low birth weight - a prospective study. Oral Health Prev Dent 2015; 13(6):537-44. https://doi.org/10.3290/j.ohpd.a34053

[6] Corbella S, Taschieri S, Del Fabbro M, Francetti L, Weinstein R, Ferrazzi E. Adverse pregnancy outcomes and periodontitis: a systematic review and meta-analysis exploring potential association. Quintessence Int 2016; 47(3):193-204. https://doi.org/10.3290/j.qi.a34980

[7] Tellapragada C, Eshwara VK, Bhat P, Acharya S, Kamath A, Bhat S, et al. Risk factors for preterm birth and low birth weight among pregnant indian women: a hospital-based prospective study. J Prev Med Public Health 2016; 49(3):165-75. https://doi.org/10.3961/jpmph. 16.022

[8] Steinberg BJ, Hilton IV, Iida H, Samelson R. Oral health and dental care during pregnancy. Dent Clin North Am 2013; 57(2):195-2 10. https://doi.org/10.1016/j.cden.2013.01.002

[9] Gaffield ML, Gilbert BJ, Malvitz DM, Romaguera R. Oral health during pregnancy: an analysis of information collected by the Pregnancy Risk Assessment Monitoring System. J Am Dent Assoc 2001; 132(7):1009-16. https://doi.org/10.142 19/jada.archive.2001.0306

[10] George A, Shamim S, Johnson M, Dahlen H, Ajwani S, Bhole S, et al. How do dental and prenatal care practitioners perceive dental care during pregnancy? Current evidence and implications. Birth 2012; 39(3):238-47. https://doi.org/10.1111/j.1523-536X.2012.00553.x

[11] Geisinger ML, Alexander DC, Dragan IF, Mitchell SC. Dental team's role in maternal and child oral health during and after pregnancy. Compend Contin Educ Dent 2019; 40(2):90-6.

[12] Boutigny H, de Moegen ML, Egea L, Badran Z, Boschin F, Delcourt-Debruyne E, et al. Oral infections and pregnancy: knowledge of gynecologists/obstetricians, midwives and dentists. Oral Health Prev Dent 2016; 14(1):417. https://doi.org/10.3290/j.ohpd.a34376

[13] Gonik B, Wilson E, Mayberry M, Joarder BY. Pregnant patient knowledge and behavior regarding perinatal oral health. Am J Perinatol 2017; 34(7):663-7. https://doi.org/10.1055/s-0036-1597134

[14] Özen B, Ozer L, Başak F, Altun C, Açıel C. Turkish women's self-reported knowledge and behavior towards oral health during pregnancy. Med Princ Pract 2012; 21(4):318-22. https://doi.org/10.1159/000334635

[15] Lubon AJ, Erchick DJ, Khatry SK, LeClerq SC, Agrawal NK, Reynolds MA, et al. Oral health knowledge, behavior, and care seeking among pregnant and recently-delivered women in rural Nepal: a qualitative study. BMC Oral Health 2018; 18(1):97. https://doi.org/10.1186/s12903-018-0564-9 
[16] Rogers SN. Dental attendance in a sample of pregnant women in Birmingham, UK. Community Dent Health 1991; $8(4): 361-8$.

[17] Jessani A, Laronde D, Mathu-Muju K, Brondani MA. Self-Perceived oral health and use of dental services by pregnant women in Surrey, British Columbia. J Can Dent Assoc 2016; 82:g28.

[18] Al Habashneh R, Guthmiller JM, Levy S, Johnson GK, Squier C, Dawson DV, et al. Factors related to utilization of dental services during pregnancy. J Clin Periodontol 2005; 32(7):815-21. https://doi.org/10.1111/j.1600-051X.2005.00739.x

[19] Saddki N, Yusoff A, Hwang YL. Factors associated with dental visit and barriers to utilization of oral health care services in a sample of antenatal mothers in Hospital Universiti Sains Malaysia. BMC Public Health 2010; 10:75. https://doi.org/10.1186/1471-2458-10-75

[20] Lim M, Riggs E, Shankumar R, Marwaha P, Kilpatrick N. Midwives' and women's views on accessing dental care during pregnancy: an Australian qualitative study. Aust Dent J 2018; 63(3):320-8. https://doi.org/10.1111/adj.12611

[21] Oral Health Care During Pregnancy Expert Workgroup. Oral Health Care During Pregnancy: A National Consensus Statement - Summary of an Expert Workgroup Meeting. Washington, DC: National Maternal and Child Oral Health $\quad$ Resource $2012 . \quad$ Available from: https://www.mchoralhealth.org/PDFs/OralHealthPregnancyConsensus.pdf. [Accessed on December 11, 2019].

[22] Riggs E, Yelland J, Shankumar R, Kilpatrick N. "We are all scared for the baby": promoting access to dental services for refugee background women during pregnancy. BMC Pregnancy Childbirth 2016; 16:12. https://doi.org/10.1186/s12884-015-0787-6

[23] Bidang Perencanaan dan Pembiayaan Dinas Kesehatan Provinsi DKI Jakarta. Profil Kesehatan Provinsi DKI Jakarta Tahun 2016. Dinas Kesehatan Provinsi DKI Jakarta. 2016. p. 87. Available from: http://www.depkes.go.id/resources/download/profil/PROFIL_KES_PROVINSI_2016/11_DKI_Jakarta_20 16.pdf. [Accessed on December 11, 2019]. [In Indonesian] 